\title{
Modeling of Adsorption Isotherms of Caffeine onto Groundnut Shell as a Low Cost Adsorbent
}

\author{
Abdoulaye Demba N'diaye ${ }^{1,2 *}$ and Mohamed Sid'Ahmed Kankou' \\ ${ }^{1}$ Unité de Recherche Eau, Pollution et Environnement, Département de Chimie, Faculté des Sciences et Technique, Université de Nouakchott Al Aasriya,
BP 880, Nouakchott, Mauritanie \\ ${ }^{2}$ Laboratoire de Chimie, Service de Toxicologie et de Contrôle de Qualité, Institut National de Recherches en Santé Publique, BP 695, Nouakchott, \\ Mauritanie
}

Received: 29/06/2020

Accepted: 05/08/2020

Published: 20/09/2020

\begin{abstract}
Caffeine is a chemical compound that has been detected in the environment and belongs to some of the most popular emerging pollutants that may cause serious environmental and human health problems. In this study, the adsorption of caffeine on groundnut shell as low cost adsorbent was investigated using the batch equilibrium method. Three adsorption isotherms namely the Langmuir, Freundlich and RedlichPeterson isotherms in their non-linear forms were applied to the adsorption equilibrium data. Both the Langmuir and Redlich-Peterson models were found to fit the adsorption isotherm data well. The retention of caffeine on the groundnut shell showed a relatively significant adsorption with a maximal quantity of $4.21 \mathrm{mg} \mathrm{g}^{-1}$. The present study showed that the powdered groundnut shell is a promising and alternative adsorbent for the removal of caffeine from aqueous solutions.
\end{abstract}

Keywords: Caffeine, Groundnut shell, Adsorbent, Isotherms

\section{Introduction}

Caffeine (1, 3, 7-Trimethyl-3,7-dihydro-1H-purin-2,6-dion) is a methylxanthine alkaloid with chemical formula $\mathrm{C}_{8} \mathrm{H}_{10} \mathrm{~N}_{4} \mathrm{O}_{2}$ [1]. Caffeine acts as psychostimulant and analeptic [2]. Many drugs contain caffeine: analgesics, antihistamines, diet pills, cold remedies, and stimulants of psychophysical activity. A potentially toxic dose is considered to be above $10 \mathrm{mg} \mathrm{kg}^{-1}$ [3]. Caffeine has a high water solubility and low octanol-water partition coefficient. Due to the low efficiency of conventional wastewater treatment process, caffeine has been detected in many surface water and ground water $[4 ; 5]$. Several methods have been applied for treatment of pharmaceutical products like photocatalytic degradation [6], micro extraction [7], oxidation [8], biodegradation [9], chlorination [10], biofiltration [11], nanofiltration and reverse osmosis [12], electrochemical oxidation [13], and adsorption [14]. Adsorption process has been a prominent method of treating aqueous effluent in industrial processes for a variety of separation and purification purposes. Besides, adsorption on activated carbon is very widely used for achieving high water purification. However, although activated carbon is a preferred adsorbent, its widespread use is restricted due to its cost. Commercially available activated carbons are still expensive due to the use of non-renewable and relatively highcost starting material [15].

In this reason, researchers have concentrated on finding alternative natural adsorbents to activated carbon. Natural adsorbents are preferred for their biodegradable, non-toxic nature, low commercial value and highly cost-effective nature. In order to decrease the cost of treatment and expand its use in wastewater treatment, we have used groundnut shell considered as solid waste of agriculture. Groundnut is cultivated in over 100 nations around the world. Main producers are China, India, Nigeria, Senegal and Sudan [16].

The aim of this study was to describe the modeling of adsorption isotherms of caffeine from aqueous solutions using groundnut shell as a low cost adsorbent. Three adsorption isotherms such as the Langmuir, Freundlich and RedlichPeterson isotherms in their non-linear forms were applied to the equilibrium data of adsorption of caffeine by groundnut shell.

\section{Materials and methods}

\subsection{Adsorbate, adsorbent and experimental procedures}

Caffeine, in analytical purity and used in the experiments directly. The caffeine solutions were prepared by diluting stocks solution to appropriate concentrations when needed [4;5]. The used groundnut shell (Figure 1) was collected from the local market of Nouakchott City in Mauritania. Details on the preparation of the groundnut shell as adsorbent, as well as some characterization parameters of the groundnut shell have been reported in previous studies [16].

*Corresponding author: Abdoulaye Demba N'diaye, (a) Unité de Recherche Eau, Pollution et Environnement, Département de Chimie, Faculté des Sciences et Technique, Université de Nouakchott Al Aasriya, BP 880, Nouakchott, Mauritanie and (b) Laboratoire de Chimie, Service de Toxicologie et de Contrôle de Qualité, Institut National de Recherches en Santé Publique, BP 695, Nouakchott, Mauritanie. E-mail : abdoulndiaye1974@ gmail.com 


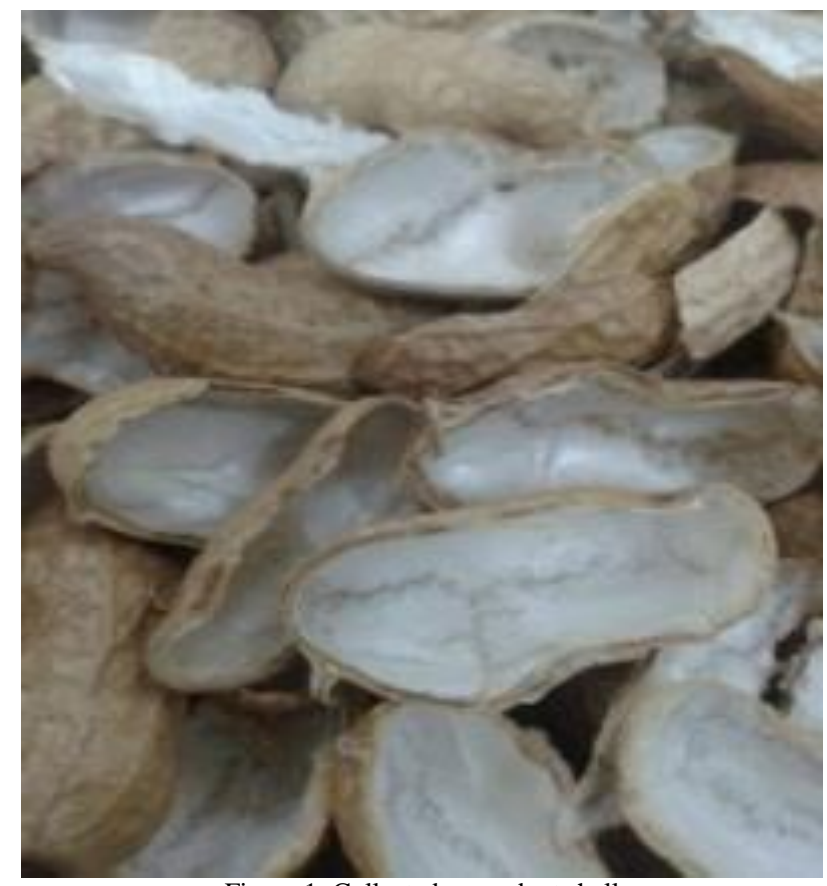

Figure 1: Collected groundnut shell

The results of physicochemical characteristics of the groundnut shell are shown in Table 1 [16].

Table 1: physicochemical characteristics of groundnut shell

\begin{tabular}{|l|l|}
\hline Parameters & Mean \\
\hline $\mathrm{pH}_{\mathrm{pzc}}$ & $5.8 \pm 0.10$ \\
\hline Moisture (\%) & $4.7 \pm 0.36$ \\
\hline Ash $(\%)$ & $2.7 \pm 0.17$ \\
\hline Volatile matter $(\%)$ & $67.1 \pm 1.57$ \\
\hline Bulk density $\left(\mathrm{g} \mathrm{mL}^{-1}\right)$ & $0.57 \pm 0.03$ \\
\hline Particle size $(\mu \mathrm{m})$ & $<100$ \\
\hline
\end{tabular}

The value of the pHpzc revealed that the studied groundnut shell possess predominantly acidic nature. From the proximate analysis, it was observed that moisture, ash and volatile matter was slightly high which may be due to its plant origin. The X-Ray fluorescence results show that the potassium, calcium, magnesium and silica oxides are major component of the groundnut shell. The Fourier Transform Infra-Red spectroscopy analyses of the groundnut shell showed some functional groups content in groundnut shell can act as proton donor and consequently coordination is possible with the positively charged caffeine [16].

\subsection{Adsorption isotherms}

The adsorption isotherms at ambient temperature are obtained by mixing $(70 \mathrm{rpm})$, for 6 hours, $0.5 \mathrm{~g}$ of groundnut shell adsorbent with $50 \mathrm{~mL}$ of caffeine solutions with different concentrations varying from 0 to $100 \mathrm{mg} \mathrm{L}^{-1}$. At the end of each experiment the agitated solution mixture was micofiltered using micro filter and the residual concentration of caffeine was determined by High Performance Liquid Chromatography (HPLC). Ultra pure water and methanol $(70: 30 \mathrm{~V} / \mathrm{V})$ were used as a mobile phase at a flow rate of $1 \mathrm{~mL} \mathrm{~min}^{-1}$ at a selected wave length of $254 \mathrm{~nm}[4 ; 5]$. The caffeine uptake amount $\mathrm{qe}_{\mathrm{e}}$ (mg of caffeine per $g$ of dried groundnut shell) was calculated using the equation (1):

$$
q_{e}=\frac{\left(C_{i}-C_{e}\right) V}{m}
$$

where $\mathrm{q}_{\mathrm{e}}$ is the caffeine concentration in groundnut shell as adsorbent $\left(\mathrm{mg} \mathrm{g}^{-1}\right), \mathrm{C}_{\mathrm{i}}$ is the initial caffeine concentration $\left(\mathrm{mg} \mathrm{L}^{-}\right.$ $\left.{ }^{1}\right) ; \mathrm{C}_{\mathrm{e}}$ is the caffeine concentration at equilibrium $\left(\mathrm{mg} \mathrm{L}^{-1}\right) ; \mathrm{V}$ is the solution volume $(\mathrm{L})$ and $\mathrm{m}$ is the mass of the groundnut shell used $(\mathrm{g})$.

\section{Results and Discussion}

The analysis of the isotherm data by fitting them to different isotherm models is an important step to find the suitable model that can be used for design purpose. Typically, the mathematical correlation, which constitutes an important role towards the modeling analysis, operational design and applicable practice of the adsorption systems, is usually depicted by graphically expressing the solid-phase against its residual concentration [17].

Over the years, a wide variety of equilibrium isotherm models such as Langmuir, Freundlich, Brunauer-Emmett-Teller, Redlich- Peterson, Dubinin- Radushkevich, Temkin, Toth, Koble-Corrigan, Sips, Khan, Hill, Flory-Huggins and RadkePrausnitz isotherm, have been formulated in terms of three fundamental approaches [18]. Kinetic consideration is the first approach to be referred. Hereby, adsorption equilibrium is defined being a state of dynamic equilibrium, with both adsorption and desorption rates are equal [19]. Whereas, thermodynamics, being a base of the second approach, can provide a framework of deriving numerous forms of adsorption isotherm models, and potential theory, as the third approach, usually conveys the main idea in the generation of characteristic curve [20]. However, an interesting trend in the isotherm modeling is the derivation in more than one approach, thus directing to the difference in the physical interpretation of the model parameters [21]. In this work, Langmuir, Freundlich ad Redlich-Peterson isotherms in their non-linear forms were applied to the equilibrium data of adsorption of caffeine by groundnut shell. The Langmuir adsorption isotherm assumes that the adsorption takes place at specific homogeneous surface sites within the adsorbent and has found successful application in many adsorption processes of monolayer adsorption [22]. The nonlinear Langmuir model can be expressed by equation (2):

$q_{e}=\frac{q_{m} K_{L} C_{e}}{1+K_{L} C_{e}}$

where $\mathrm{q}_{\mathrm{e}}$ is the amount of caffeine adsorbed per unit mass of groundnut shell (mg. $\left.\mathrm{g}^{-1}\right), \mathrm{k}_{\mathrm{L}}$ is the Langmuir constant related to the adsorption capacity $\left(\mathrm{L} \mathrm{g}^{-1}\right), \mathrm{C}_{\mathrm{e}}$ is the concentration of caffeine in the solution at equilibrium $\left(\mathrm{mg} \mathrm{L}^{-1}\right), \mathrm{q}_{\mathrm{m}}$ is the maximum uptake per unit mass of groundnut shell $\left(\mathrm{mg}^{-\mathrm{g}^{-1}}\right)$. The factor of separation of Langmuir, $\mathrm{R}_{\mathrm{L}}$, which is an essential factor characteristic of this isotherm is calculated by equation (3):

$$
R_{L}=\frac{1}{\left(1+k_{L} C_{0}\right)}
$$


where $\mathrm{C}_{0}$ is the higher initial concentration of caffeine and $\mathrm{K}_{\mathrm{L}}$ is the Langmuir constant. The $\mathrm{R}_{\mathrm{L}}$ value implies the adsorption to be defavourable $\left(R_{L}>1\right)$, linear $\left(R_{L}=1\right)$, favourable $\left(0<R_{L}<1\right)$, or irreversible $\left(R_{L}=0\right)$. The Freundlich isotherm is an empirical equation employed to describe heterogeneous systems [22]. The nonlinear representation of the Freundlich model is as in equation (4):

$$
q_{e}=K_{F} C_{e}^{1 / n}
$$

Where $\mathrm{K}_{\mathrm{F}}\left(\mathrm{mg} \mathrm{g}^{-1}\right)\left(\mathrm{L} \mathrm{mg}^{-1}\right)^{\mathrm{n}}$ and $1 / \mathrm{n}$ are the Freundlich constants related to adsorption capacity and adsorption intensity, respectively. The Redlich-Peterson isotherm model combines elements from both the Langmuir and Freundlich equation and the mechanism of adsorption is a hybrid one and does not follow ideal monolayer adsorption. It is used as a compromise to improve the fit by Langmuir or Freundlich [23]. The nonlinear representation of the Redlich-Peterson model is as in equation (5):

$q_{e}=\frac{K_{R P} C_{e}}{1+\alpha_{R P} C_{e}^{n}}$

where $K_{\mathrm{RP}}\left(\mathrm{L} \mathrm{g} \mathrm{g}^{-1}\right)$ and $\alpha_{\mathrm{RP}}\left(\mathrm{L} \mathrm{mol}^{-1}\right)$ are the Redlich-Peterson isotherm constants, while $\mathrm{n}$ is the exponent, which lies between 0 and 1. Two errors functions including the Sum of the Squares of the Errors (SSE) and the correlation coefficient $\left(\mathrm{R}^{2}\right)$ were used to verify the model for the adsorption systems [24;25]. The SSE and $\mathrm{R}^{2}$ values, by using the Solver Excel, are determined respectively by following equations (6) and (7):

$$
\begin{aligned}
& \operatorname{SSE}=\left(q_{\text {exp }}-q_{\text {mod }}\right)^{2} \\
& \mathrm{R}^{2}=100\left(1-\frac{\left\|\mathrm{q}_{\text {exp }}-\mathrm{q}_{\text {mod }}\right\|^{2}}{\left\|\mathrm{q}_{\text {exp }}-\mathrm{q}_{\text {avr }}\right\|^{2}}\right)
\end{aligned}
$$

where $\mathrm{q}_{\exp }\left(\mathrm{mg} \mathrm{g}^{-1}\right)$ is equilibrium capacity from the experimental data, qavr $\left(\mathrm{mg} \mathrm{g}^{-1}\right)$ is equilibrium average capacity from the experimental data and $\mathrm{q}_{\mathrm{mod}}\left(\mathrm{mg} \cdot \mathrm{g}^{-1}\right)$ is equilibrium from model. So that $R^{2} \leq 100$ - the closer the value is to 100 , the more perfect is the fit. Figure 2 shows the experimental data fitted to non-linear forms of the three isotherms, using Solver Excel, for caffeine adsorption by groundnut shell. The isotherms constants related to Langmuir, Freundlich and Redlich-Peterson models determined from the plots shown in Figure 2 are listed in Table 2. The values of $R_{L}, K_{L}$ and $1 / n$ are in between 0 and 1 give an indication of the favorability of the adsorption of caffeine onto groundnut shell. It is interesting to note that the value of $\mathrm{K}_{\mathrm{L}}<0.1$ is a sign of low surface energy, which indicates stronger bonding between caffeine and the groundnut shell as adsorbent.

As can be clearly seen from Table 2, the Langmuir and Redlich-Peterson models gave the highest $\mathrm{R}^{2}$ and low SSE value showing that the adsorption isotherms of caffeine by groundnut shell were best described by these two models. The suitability of the Langmuir isotherm to fit the data was confirmed by the exponent value of the Redlich-Peterson model, n, which was near to one. It should be noted that most of the isotherm adsorption studies of pharmaceutical products on various adsorbents follow the Langmuir isotherm model [26-35].

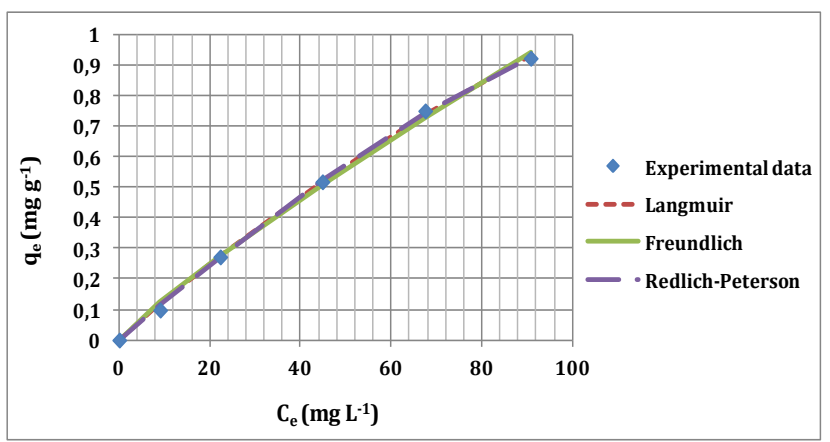

Figure 2: Comparison between the experimental and predicted isotherms for the adsorption of caffeine by groundnut shell

Table 2: Parameters isotherm model for caffeine retention on the Groundnut Shell

\begin{tabular}{|c|c|c|}
\hline \multirow{4}{*}{ Langmuir } & Parameters & Values \\
\hline \multirow{4}{*}{ Freundlich } & $\mathbf{q}_{\mathbf{m}}$ & 4.21 \\
\cline { 2 - 3 } & $\mathbf{K}_{\mathbf{L}}$ & 0.0031 \\
\cline { 2 - 3 } & $\mathbf{R}_{\mathbf{L}}$ & 0.76 \\
\cline { 2 - 3 } & $\mathbf{S S E}$ & 0.00065 \\
\cline { 2 - 3 } & ${ }^{2} \mathbf{R}(\%)$ & 99.87 \\
\hline \multirow{4}{*}{ Redlich-Peterson } & $\mathbf{1} / \mathbf{n}$ & 0.87 \\
\cline { 2 - 3 } & $\mathbf{K}_{\mathbf{F}}$ & 0.018 \\
\cline { 2 - 3 } & $\mathbf{S S E}$ & 0.0018 \\
\cline { 2 - 3 } & ${ }^{2} \mathbf{R}(\%)$ & 99.63 \\
\hline & $\mathbf{K}_{\mathbf{R P}}$ & 0.0125 \\
\cline { 2 - 3 } & $\mathbf{\alpha}_{\mathbf{R P}}$ & 0.00018 \\
\cline { 2 - 3 } & $\mathbf{n}$ & 0.96 \\
\cline { 2 - 3 } & $\mathbf{S S E}$ & 0.00034 \\
\cline { 2 - 3 } & ${ }^{2} \mathbf{R}(\%)$ & 99.93 \\
\hline \multirow{4}{*}{} & &
\end{tabular}

Table 3: Adsorption capacities of different adsorbents for the uptake of different pharmaceutical products from their aqueous solutions

\begin{tabular}{|l|l|l|l|}
\hline Adsorbate & Adsorbent & $\mathbf{q}_{\mathbf{m}}\left(\mathbf{m g ~ g}^{-1}\right)$ & Ref. \\
\hline Carbamazepine & \multirow{2}{*}{ Cork } & 0.37 & \multirow{2}{*}[36]{} \\
\cline { 3 - 3 } Ibuprofen & & 0.32 & \\
\hline \multirow{2}{*}{ Paracetamol } & Sugar Can Bagasse & 0.12 & \multirow{2}{*}[37]{} \\
\cline { 2 - 3 } & Vegetable Sponge & 0.037 & \\
\hline \multirow{3}{*}{ Paracetamol } & Grape Stalk & 1.74 & \multirow{2}{*}[38]{} \\
\cline { 2 - 3 } & Yonimbe Bark & 0.77 & \\
\cline { 2 - 3 } & Cork Bark & 0.99 & {$[39]$} \\
\hline Ibuprofen & Parthenium weed & 3.8 & {$[40]$} \\
\hline Aspirin & Posidonia Oceanica & 1.638 & \\
\hline Caffeine & $\begin{array}{l}\text { Dehydrated Sewage } \\
\text { Sludge }\end{array}$ & 0.956 & \\
\hline \multirow{2}{*}{ Caffeine } & Banana peel & 2.29 & {$[41]$} \\
\hline
\end{tabular}

The monolayer adsorption capacity, $\mathrm{q}_{\mathrm{m}}$, was found to be 4.21 $\mathrm{mg} \mathrm{g}^{-1}$. A list showing the adsorption capacity of different low cost adsorbents for the adsorption of different pharmaceutical products from their aqueous solutions is given in Table 3. From Table 3, it is observed that the adsorption capacities of groundnut shell adsorbent for pharmaceutical product uptake are superior with other low cost adsorbents. It can be concluded that the groundnut shell without any treatment applied in this work can be 
considered a promising material to be used for caffeine adsorption.

\section{Conclusions}

The equilibrium data were analyzed using non-linear method by fitting them to the Langmuir, Freundlich and Redlich-Peterson model equations. Both the Langmuir and Redlich-Peterson isotherms represent well the experimental adsorption data. The maximum adsorption capacity was found to be $4.21 \mathrm{mg} \mathrm{g}^{-1}$. Groundnut shell could be considered as potential low cost adsorbent for caffeine removal from aqueous solution. For future studies, the usability of groundnut shell for pharmaceutical products removal from real wastewater will be tested and as comparison, a fixed bed column will be employed to investigate the effect of reactor design.

\section{Ethical issue}

Authors are aware of, and comply with, best practice in publication ethics specifically with regard to authorship (avoidance of guest authorship), dual submission, manipulation of figures, competing interests and compliance with policies on research ethics. Authors adhere to publication requirements that submitted work is original and has not been published elsewhere in any language.

\section{Competing interests}

The authors declare that there is no conflict of interest that would prejudice the impartiality of this scientific work.

\section{Authors' contribution}

All authors of this study have a complete contribution for data collection, data analyses and manuscript writing.

\section{References}

1. Ghosh, M., Manoli, K., Shen, X., Wang, J., Ray, A.K. Solar photocatalytic degradation of caffeine with titanium dioxide and zinc oxide nanoparticles. J. Photochem. Photobiol. Chem. 2019, 377, 1-7.

2. Alvarez, S., Ribeiro, R., Gomes, H., Sotelo, J., García, J., Synthesis of carbon xerogels and their application in adsorption studies of caffeine and diclofenac as emerging contaminants. Chem. Eng. Res. Des.2015, 95, 229-238.

3. Anastopoulos, I., Pashalidis, I., Orfanos, A. G., Manariotis, I. D., Tatarchuk, T., Sellaoui, L., ... Núñez-Delgado, A. Removal of caffeine, nicotine and amoxicillin from (waste)waters by various adsorbents. A review. Journal of Environmental Management, 2020, 261, 110236

4. N'diaye A.D., Kankou M.S.A, Valorization of Balanites aegyptiaca seeds from Mauritania: Modeling of adsorption isotherms of caffeine from aqueous solution. Journal of Environmental Treatment Techniques, 2019, 7, 3, 450-455

5. N'diaye A.D, Kankou M.S.A, Sorption of caffeine onto low cost sorbent: Application of two and three-parameter isotherm models. Applied Journal of Environmental Engineering Science, 2019, 5, 3, 263-272.

6. Varma K.S., Tayade R.J., Shah K.J., Joshi P.A., Shukla A.D., Gandhi V.G, Photocatalytic degradation of pharmaceutical and pesticide compounds (PPCs) using doped $\mathrm{TiO}_{2}$ nanomaterials: A review. WaterEnergy Nexus, 2020.

7. Wang Y., Dai X, He X., Chen L., Hou X., X. MIL-101(Cr)@GO for dispersive micro-solid-phase extraction of pharmaceutical residue in chicken breast used in microwave-assisted coupling with HPLC-MS/MS detection. Journal of Pharmaceutical and Biomedical Analysis, 2017, $145,440-446$,
8. Wang C., Siriwardane D.A., Jiang W, Mudalige T, Quantitative analysis of cholesterol oxidation products and desmosterol in parenteral liposomal pharmaceutical formulations. International Journal of Pharmaceutics, 2019, 118576

9. Wei Z, Li W, Zhao D, Seo Y, Spinney R, Dionysiou D.D, ... Xiao R, Electrophilicity index as a critical indicator for the biodegradation of the pharmaceuticals in aerobic activated sludge processes. Water Research, 2019.

10. Liu Y.J, Liu H.S, Hu C.Y, Lo S.L., Simultaneous aqueous chlorination of amine-containing pharmaceuticals. Water Research, 2019.

11. Fu, J., Lee, W.-N., Coleman, C., Nowack, K., Carter, J., Huang, C.$\mathrm{H}$. Removal of pharmaceuticals and personal care products by two-stage biofiltration for drinking water treatment. Science of The Total Environment, 2019, 664, 240-248

12. Couto C.F., Santos A.V., Amaral M.C.S., Lange L.C., de Andrade L.H., Foureaux A.F.S., Fernandes B.S. Assessing potential of nanofiltration, reverse osmosis and membrane distillation drinking water treatment for pharmaceutically active compounds (PhACs) removal. Journal of Water Process Engineering, 2020, 33, 101029,

13. López Zavala M.A., Vega D.A., Álvarez Vega J.M., Castillo Jerez O.F., Cantú Hernández R.A, Electrochemical oxidation of acetaminophen and its transformation products in surface water: effect of $\mathrm{pH}$ and current density. Heliyon, 2020, 6 (2), e03394,

14. Bunmahotama W., Lin T., Yang, X. Prediction of adsorption capacity for pharmaceuticals, personal care products and endocrine disrupting chemicals onto various adsorbent materials. Chemosphere, 2019, 124658.

15. Pan B.,Pan Bi, Zhang W., Zhang Q., Zhang Q., Zhang S. Adsorptive removal of phenol from aqueous phase by using a porous acrylic ester polymer. J. Hazard. Mater.2008, 157 (2-3), 293-299,

16. N'diaye A.D., Bollahi M.A., Kankou M.S.A. Sorption of Paracetamol onto Groundnut Shell from aqueous solution. Journal Material of Environmental Science,2019, 10, 6, 553-562,

17. Ncibi M.C., Applicability of some statistical tools to predict optimum adsorption isotherm after linear and non-linear regression analysis, $J$. Hazard. Mater. 2008, 153, 207-212.

18. Malek A., Farooq S., Comparison of isotherm models for hydrocarbon adsorption on activated carbon, 1996, AIChE J. 42 (11), 3191-3201.

19. Langmuir I., The constitution and fundamental properties of solids and liquids, J. Am. Chem. Soc. 1916, 38 (11), 2221-2295.

20. Dubinin M.M., The potential theory of adsorption of gases and vapors for adsorbents with energetically non-uniform surface, Chem. Rev. 1960, 60, 235-266.

21. Ruthven D.M. Principles of Adsorption and Adsorption Processes, Wiley, New York, 1984.

22. Machrouhi A., Farnane M., Elhalil A., Abdennouri M., Tounsadi H., Barka N., Heavy metals biosorption by Thapsia transtagana stems powder: kinetics, equilibrium and thermodynamics, Moroccan Journal of Chemistry, 2019, 7, 1, 098-110.,

23. Dhaouadi H., M'Henni F., Vat dye Sorption onto crude dehydrated sewage sludge, Journal of Hazardous Materials,2009, 164 (2-3), 448 458 .

24. Zakhama S., Dhaouadi H., M'Henni F., Nonlinear modelisation of heavy metal removal from aqueous solution using Ulva lactuca algae, Bioressource Technology, 2011,102, 786-796,

25. Subramanyam B., Das A., Linearised and non-linearised isotherm models optimization analysis by error functions and statistical means, Journal of Environmental Health Science \& Engineering, 2014, 12:92,

26. Bekci Z., Seki Y., Yurdakoc M., Equilibrium studies for trimethoprim adsorption on montmorillonite KSF. Journal of Hazardous Materials, 2006, 133(1-3), 233-242.

27. Fukahor S., Fujiwara T., Ito R., Funamizu N., pH-Dependent adsorption of sulfa drugs on high silica zeolite: Modeling and kinetic study, Desalination, 2011, 275 (1-3), 237-242.

28. Baccar R., Sarrà M., Bouzid J., Feki M., Blánquez, P. Removal of pharmaceutical compounds by activated carbon prepared from agricultural by-product. Chemical Engineering Journal, 2012, 211-212, 310-317. 
29. Ferreira R.C., de Lima H.H.C., Cândido A.A., Couto Junior O.M., Arroyo P.A., de Carvalho K.Q., Gauze G.F., de Barros M.A.S.D., Adsorption of paracetamol using activated carbon of dende and babassu coconut mesocarp, Int. J. of Biol., Biomol., Agric., Food and Biotechnol. Eng., 2015, 9,575-58 0.

30. Miao M.S., Liu Q., Shu L., Wang Z., Liu Y.Z., Kong Q., Removal of cephalexin from effluent by activated carbon prepared from alligator weed: Kinetics, isotherms, and thermodynamic analyses, Process Safety and Environmental Protection, 2016, 104, 481-489.

31. Boudrahem N, Delpeux-Ouldriane S., Khenniche L., Boudrahem F., Aissani-Benissad F., Gineys M., Single and mixture adsorption of clofibric acid, tetracycline and paracetamol onto Activated carbon developed from cotton cloth residue. Process Safety and Environmental Protection, 2017, 111, 544-559.

32. Beltrame, K.K., Cazetta, A.L., de Souza, P.S.C., Spessato, L., Silva, T.L., Almeida, V.C., Adsorption of caffeine on mesoporous activated carbon fibers prepared from pineapple plant leaves. Ecotoxicol. Environ. Saf. 2018, 147, 64e71.

33. Paredes-Laverde M., Silva-Agredo J., Torres-Palma R.A., Removal of norfloxacin in deionized, municipal water and urine using rice (Oryza sativa) and coffee (Coffea arabica) husk wastes as natural adsorbents. Journal of Environmental Management, 2018, 213, 98-108.

34. Paredes-Laverde M., Salamanca M., Silva-Agredo J., Manrique- Losada L., Torres-Palma R.A., Selective removal of acetaminophen in urine with activated carbons from rice (Oryza sativa) and coffee (Coffea arabica) husk: Effect of activating agent, activation temperature and analysis of physical-chemical interactions. Journal of Environmental Chemical Engineering, 2019, 103318.

35. N'diaye A.D., Kankou M.S.A. Modeling of adsorption isotherms of pharmaceutical products onto various adsorbents: A Short Review. Journal Material and Environmental Science, 2020, 11, 8, 1264-1276

36. Dordio, A.V., Gonçalves, P., Texeira, D., Candeias, A.J., Castanheiro, J.E., Pinto, A.P., Carvalho, A.J.P., Pharmaceuticals sorption behaviour in granulated cork for the selection of a support matrix for a constructed wetlands system. Int. J. Environ. Anal. Chem. 2011, 91, 615-631.

37. Ribeiro A.V.F.N., Belisário M., Galazzi R.M., Balthazar D.C., Godoi Pereir M., Ribeiro J.N., Evaluation of two bioadsorbents for removing paracetamol from aqueous media, Electronic Journal of Biotechnology, $2011,14,6$,

38. Villaescusa I., Fiol N., Poch J., Bianchi A., Bazzicalupi C., Mechanism of paracetamol removal by vegetable wastes: The contribution of $\pi-\pi$ interactions, hydrogen bonding and hydrophobic effect, Desalination, 2011, 270, (1-3), 135 142,

39. Mondal, S., Aikat, K., Halder, G. Biosorptive uptake of ibuprofen by chemically modified Parthenium hysterophorus derived biochar: equilibrium, kinetics, thermodynamics and modeling. Ecol. Eng.2016, 92, 158-172,

40. Ferchichi M., Dhaouadi H., Sorption of paracetamol onto biomaterials, Water Science and Technology, 2016, 74, (1),287-294,

41. Ribeiro A.V.F.N., Da Silva A.R., Ca Cunha T.P., Dos Santos R.T.L., De Oliveira J.P., Pereira E.V., Licinio M.V.V.J., De Godoi Pereira M., Dos Santos A.V., Ribeiro J.N., Banana Peel for Acetylsalicylic Acid Retention. Journal of Environmental Protection, 2016, 7, 1850-1859,

42. Portinho R., Zanella O., Féris L.A., Grape stalk application for caffeine removal through adsorption. Journal of Environmental Management; 2017, 202: 178-187, 